\title{
Inclusão da camomila no desempenho, comportamento e estresse em codornas durante a fase de recria
}

\author{
Chamomile inclusion on performance, behavior and stress in immature quails
}

\author{
Rafael Henrique Marques $^{*}$ Rodrigo Antonio Gravena $^{\mathrm{I}}$ Janaina Della Torre da Silva ${ }^{\mathrm{I}}$ \\ Fabricio Hirota Hada ${ }^{I}$ Vanessa Karla Silva ${ }^{\mathrm{I}}$ Ramon Diniz Malheiros ${ }^{\text {II }}$ \\ Vera Maria Barbosa de Moraes ${ }^{\text {III }}$
}

\section{RESUMO}

Este estudo teve como objetivo avaliar o efeito da Matricaria chamomila sobre o estresse de codornas japonesas na fase de recria (28 a 42 dias de idade). Foram utilizadas 192 codornas com 28 dias de idades, distribuídas em blocos casualizados e submetidas às dietas com 0, 250, 500 e 750mg de camomila/kg de ração, totalizando quatro tratamentos, com oito repetições e seis aves por parcela. Foram avaliados os parâmetros de desempenho (consumo diário de ração, conversão alimentar e ganho de peso), comportamentais (tempo em imobilidade tônica, ferimentos corporais e agressividade) e fisiológicos (concentração plasmática de corticosterona e relação heterófilo:linfócito). Os resultados obtidos demonstraram que a camomila adicionada na dieta não foi capaz de alterar os parâmetros de desempenho, bem como os de comportamento e fisiológicos.

Palavras-chave: corticosterona, Coturnix coturnix japonica, estresse, imobilidade tônica, Matricaria chamomila, relação heterófilo:linfócito.

\section{ABSTRACT}

The objective of this study was to test the effect of Matricaria chamomila on the stress of the Japanese quails in the rearing period. In the rearing phase, from 28 to 42 days old, 192 quails were lodged to cages and allotted to completely randomized blocks design, with four diets $(0 ; 250 ; 500$ and $750 \mathrm{mg}$ of chamomile/kg of ration), with eight replicates and six birds per cage. Performance (feed intake, body weight gain, and feed conversion ratio), behavior (body injury, tonic immobility and focal observation) and physiological parameters (corticosterone plasmatic and heterophil/lymphocyte ratio) were evaluated. The tested chamomile levels did not affect performance, behavior and physiological parameters of quails in the rearing phase.
Key words: corticosterone, Coturnix coturnix japonica, heterophil lymphocyte ratio, Matricaria chamomile, stress, tonic immobility.

\section{INTRODUÇÃO}

O hábito de se consumir carne e ovos de codorna vem aumentando a cada dia, fato que pode ser comprovado pelos dados apresentados pelo IBGE (2007), o qual destaca que o efetivo de cabeças de codornas no Brasil, em 1995, era de aproximadamente três milhões e, em 2007, esse número saltou para sete milhões e duzentos mil aproximadamente. Dentre outras vantagens na criação, as codornas destacam-se pela boa conversão alimentar, pela maturidade sexual precoce, pela alta produtividade, pelos pequenos investimentos iniciais, pelo fácil manejo e pela resistência às doenças e principalmente pelo rápido retorno financeiro. Além disso, tanto a carne, quanto os ovos, são excelentes fontes de nutrientes, fundamentalmente proteína (SILVA et al., 1989; MURAKAMI \& ARIKI, 1998; SINGH \& NARAYAN, 2002).

No entanto, as codornas podem apresentar comportamentos indesejáveis, como bicagem das penas, agressão, desvio social e depressão (MILLS \& FAURE, 1990; JONES, 1996), sendo o estresse o principal fator desencadeador desses

\footnotetext{
IPrograma de Pós-graduação em Zootecnia, Faculdade de Ciências Agrárias e Veterinária (FCAV), Universidade Estadual Paulista (UNESP). Avenida Ariovaldo Esbaile, nº 321, 14883-328, Jaboticabal, SP, Brasil. E-mail: rafael_zoo03@hotmail.com.*Autor para correspondência.

IICampus Experimental, Faculdade de Zootecnia, UNESP, Dracena, SP, Brasil.

IIIDepartamento de Zootecnia, FCAV, UNESP, Jaboticabal, SP, Brasil.
} 
comportamentos. Portanto, esses efeitos podem afetar de forma direta ou indireta a saúde e a produtividade desses animais (DUNCAN, 1981; MILLS \& FAURE, 1990; JONES \& MILLS, 1999). Ferimentos causados por bicadas agressivas é um problema de extrema importância, pois diz respeito ao bem-estar das codornas (WECHSLER \& SCHMID, 1998).

Quando expostas a predadores ou a situações novas, as aves apresentam comportamento de medo, levando ao estado de hipnose ou à imobilidade, persistindo durante alguns segundos até horas. Esse estado de hipnose, medo ou estresse pode ser avaliado pela tomada do tempo em imobilidade tônica (JONES \& MILLS, 1999).

Quando submetidas a situações de estresse, as aves passam por alguns processos fisiológicos, como o aumento na liberação de hormônios corticotróficos, reduzindo a quantidade de linfócitos circundantes e proporcionando aumento na relação heterófilo:linfócito (MACARI et al., 2002). GROSS \& SIEGEL (1983) mostraram que H:L é a medida mais confiável para indicação do nível de estresse em frangos de corte. A taxa de H:L poderia ser usada não somente para seleção de aves resistentes ao estresse térmico, mas também como a outras resistências, incluindo doenças (AL-MURRANI et al., 1997).

Uma alternativa para controlar o comportamento agressivo das codornas seria o uso de fitoterápicos, medicamentos feitos de partes de plantas cujos princípios ativos não foram purificados, como chás, extratos e tinturas. São obtidos por meio de processos tecnologicamente adequados com finalidades profiláticas, curativas e paliativas (ALBUQUERQUE, 2004).

O fitoterápico em estudo neste trabalho foi a Matricaria chamomila, conhecida popularmente como camomila-alemã, camomila-azul, camomila-comum e matricaria. É uma herbácea anual empregada como analgésica, anti-inflamatória, calmante, ansiolítica, cicatrizante, antiespasmódica, desinfetante e emoliente (DUARTE \& LIMA, 2003; GOMAA et al., 2003). A atividade ansiolítica e sedativa da camomila vem sendo atribuída à apigenina, um flavonoide isolado a partir da flor de camomila desidratada (UNSELD et al., 1989). AVALLONE et al. (2000) testaram os efeitos sedativos e ansiolíticos da apigenina em ratos adultos e observaram que, em doses de 25 e $50 \mathrm{mg} \mathrm{kg}^{-1}$, exerceram atividade sedativa, mas não mostrou um claro efeito ansiolítico e relaxante muscular, sendo esses efeitos atribuídos à outros compostos da camomila.

Nesse sentido, o presente trabalho teve como objetivos estabelecer o nível adequado de inclusão de camomila na ração de codornas como modulador de estresse e avaliar os efeitos da adição desse fitoterápico no desempenho, no tempo de permanência em imobilidade tônica e na agressividade, por meio dos danos causados por bicadas e pela observação direta do comportamento agressivo na fase de recria.

\section{MATERIAL E MÉTODOS}

Foram utilizadas codornas com um dia de idade e criadas no piso em círculo de proteção, com cama de maravalha, no período de um a 25 dias de idade. Receberam água e ração à vontade, sendo utilizados comedouros e bebedouros infantis para frangos de corte. O fornecimento de calor foi feito com o uso de lâmpadas de infravermelho.

Aos 25 dias de idade, as codornas foram vacinadas contra Newcastle (estirpe NewVac B1), por via ocular, e transferidas para as gaiolas de postura para se adaptarem e, aos 28 dias de idade, 192 aves não debicadas foram distribuídas em um delineamento em blocos ao acaso, para se controlar o efeito inicial do peso (80-110g), e foram submetidas a quatro tratamentos ( 0 - controle; 250; 500 e 750mg de Matricaria chamomila $\mathrm{kg}^{-1}$ de ração), com oito repetições e seis aves por parcela. O extrato de camomila adicionado na dieta das aves experimentais corresponde à inflorescência da camomila. Após a colheita, essa inflorescência foi submetida a um método de secagem à sombra e posteriormente ao processo de esterilização por radiação gama. Depois essa inflorescência foi moída, formando um pó fino e higroscópico de coloração amarelada e odor aromático agradável, obtendo-se, assim, a apigenina. As rações foram isoproteicas e isoenergéticas e seguiram as tabelas de composição de ingredientes de ROSTAGNO et al. (2005) e as exigências nutricionais de acordo com o proposto por MURAKAMI et al. (1993) e NRC (1994), sendo acrescentada $\boldsymbol{M}$. chamomila, de acordo com os tratamentos (Tabela 1). Além dessas aves, outras 48 codornas foram distribuídas igualmente em duas gaiolas por tratamento, totalizando oito gaiolas com seis aves cada, com o objetivo de se realizar a substituição das aves no caso de eventuais mortes, havendo a preocupação em deixar constante a densidade populacional no experimento.

Os parâmetros de desempenho avaliados foram: consumo diário de ração ( $\mathrm{g} \mathrm{dia}^{-1}$ ), ganho de peso, conversão alimentar (consumo de ração/ganho de peso) e mortalidade.

A avaliação do tempo de imobilidade tônica (TIT) foi realizada da seguinte forma: todas as aves de uma mesma parcela foram colocadas em uma caixa, e 
Efeito da inclusão da camomila no desempenho, comportamento e estresse em codornas durante a fase de recria. 417

Tabela 1 - Composição percentual e calculada das rações fornecidas às aves na fase de recria de acordo com os tratamentos

\begin{tabular}{|c|c|c|c|c|}
\hline \multirow{2}{*}{ Ingredientes\% } & \multicolumn{4}{|c|}{-Camomila (mg kg-1 de ração) } \\
\hline & 0 & 250 & 500 & 750 \\
\hline Milho & 58,220 & 58,220 & 58,220 & 58,220 \\
\hline Farelo de soja & 30,413 & 30,413 & 30,413 & 30,413 \\
\hline Farelo de trigo & 7,705 & 7,680 & 7,660 & 7,630 \\
\hline Fosfato bicálcico & 1,882 & 1,882 & 1,882 & 1,882 \\
\hline Calcário calcítico & 0,660 & 0,660 & 0,660 & 0,660 \\
\hline $\mathrm{Sal} / \mathrm{NaCl}$ & 0,300 & 0,300 & 0,300 & 0,300 \\
\hline Suplemento mineral e vitamínico ${ }^{1}$ & 0,500 & 0,500 & 0,500 & 0,500 \\
\hline Lisina & 0,320 & 0,320 & 0,320 & 0,320 \\
\hline Camomila & 0 & 0,025 & 0,050 & 0,075 \\
\hline \multirow[t]{2}{*}{ Total } & 100,00 & 100,00 & 100,00 & 100,00 \\
\hline & \multicolumn{4}{|c|}{----Composição calculada---- } \\
\hline Proteína Bruta (\%) & 20 & 20 & 20 & 20 \\
\hline Energia Metabolizável (kcal kg-1) & 2800 & 2800 & 2800 & 2800 \\
\hline Cálcio (\%) & 0,80 & 0,80 & 0,80 & 0,80 \\
\hline Fósforo disponível (\%) & 0,45 & 0,45 & 0,45 & 0,45 \\
\hline Lisina (\%) & 1,30 & 1,30 & 1,30 & 1,30 \\
\hline Metionina + Cistina (\%) & 0,64 & 0,64 & 0,64 & 0,64 \\
\hline Metionina (\%) & 0,31 & 0,31 & 0,31 & 0,31 \\
\hline
\end{tabular}

${ }^{1}$ Suplemento vitamínico e mineral - Composição kg-1 do produto: Ácido fólico, 140mg; Ácido pantotênico, 1600mg; Biotina, 12mg; Colina, 65mg; Niacina, 3000mg; Piridoxina, 400mg; Riboflavina, 800mg; Tiamina, 200mg; Vit. A, 1600000UI kg-1. Vit. B12, 2000mg; Vit. D3, 400000UI kg-1; Vit. E, 3000mg; Vit. K3, 400mg; Cobre, 1200mg; Ferro, 10000mg; Iodo, 240mg; Manganês, 12000mg; Selênio, 80mg; Zinco, 12000mg; Metionina, 353430mg; Antifúngico, 3000mg; Antioxidante, 990mg.

uma codorna por vez foi virada abruptamente e colocada na posição de decúbito dorsal, em uma superfície plana. Foi realizada uma pressão sobre o peito da ave por três segundos antes do início da contagem do tempo, que foi realizada com auxílio de um cronômetro digital. Para ser considerado estado de imobilidade tônica, a ave deveria permanecer imóvel por no mínimo 10 segundos (HEIBLUM et al., 1998).

As observações de agressividade, segundo SAVORY et al. (1999), foram realizadas da seguinte forma: 1) o comportamento agressivo (montando e bicando) e comportamento não agressivo (come, bebe, coça e ócio) foram avaliados pela observação direta e contínua das aves de cada gaiola, consistindo na observação e posterior anotação desses comportamentos durante a amostragem focal por cinco minutos em cada gaiola e sendo realizadas três observações semanais pelo período da manhã no mesmo horário do dia, durante o período do $28^{\circ}$ ao do 350 dia de idade das aves; e 2) a intensidade dos ferimentos corporais e o TIT no período da manhã foram avaliados pela presença individual dos ferimentos ou ausência de lesão nas diferentes partes do corpo (cabeça e corpo) das aves ao final do $28^{\circ}$ ao $35^{\circ}$ dia de idade. As análises estatísticas não paramétricas de atividades realizadas e dos ferimentos corporais das codornas foram feitas pela comparação de médias pelo teste de Qui-quadrado, a 5\% de probabilidade.

Ao final do $28^{\circ}$ e do $35^{\circ}$ dia de idade, foram coletadas amostras de sangue de duas aves por parcela, totalizando 64 amostras semanais. Com o uso de uma seringa com EDTA, cerca de $0,1 \mathrm{~mL}$ de sangue/ ave foi obtido por punção da veia braquial, utilizado para a confecção das lâminas para posterior cálculo da relação de heterófilo:linfócito. Segundo a metodologia de CAMPO \& DÁVILA, (2002), 100 leucócitos, inclusive os granulares (heterófilo, eosinófilo e basófilo) e não granulares (linfócito e monócito), foram contados utilizando-se microscópio óptico. Após esse procedimento, o número de heterófilos foi dividido pelo número de linfócitos, por lâmina, determinando-se assim a relação entre eles. Com auxílio de outra seringa heparinizada, foram retirados das mesmas aves aproximadamente $0,5 \mathrm{~mL}$ sangue ave ${ }^{-1}$, que foram centrifugados a 3000rpm, por 10 minutos, para a obtenção do plasma. O plasma foi então separado e armazenado $\mathrm{a}-20^{\circ} \mathrm{C}$ para posterior avaliação dos níveis de corticosterona pela análise do Radioimunoensaio (MALHEIROS et al., 2003).

Para as análises estatísticas dos resultados obtidos, foi utilizado o procedimento GLM do SAS ${ }^{\circledR}$ (STATISTICAL ANALYSIS SYSTEM, 1995). Para 
verificar a significância entre as médias dos tratamentos, foi utilizado o teste de Tukey, a 5\% de probabilidade.

\section{RESULTADOS E DISCUSSÃO}

Os diferentes níveis de camomila utilizados não influenciaram significativamente o desempenho das aves na fase de recria (Tabela 2). Esses resultados estão de acordo com os estudos realizados por GRAVENA et al. (2006) e SILVA(2006). GRAVENAet al. (2006) não obtiveram diferenças significativas no desempenho das codornas, na fase de recria, recebendo dietas suplementadas com valeriana. SILVA (2006) também não observou diferença significativa nos resultados de desempenho de codornas quando foi adicionada passiflora em níveis crescentes, em dietas de codornas.

Durante o período não houve mortalidade das aves experimentais.

Verificou-se que houve diferença significativa $(P<0,05)$ para a duração do tempo em imobilidade tônica das codornas submetidas aos diferentes tratamentos (Tabela 2), e as aves que receberam $750 \mathrm{mg}$ de camomila $\mathrm{kg}^{-1}$ de dieta permaneceram menor tempo em imobilidade tônica, em relação aquelas que receberam $500 \mathrm{mg} \mathrm{kg}^{-1}$, porém esses resultados não diferiram dos demais tratamentos. Semelhante aos resultados obtidos, SILVA et al. (2007) concluíram que as codornas alimentadas com ração controle apresentaram uma maior duração do tempo do que os tratamentos com passiflora, sugerindo assim a ocorrência do efeito calmante desse fitoterápico.

Os resultados obtidos para relação de heterófilo:linfócito e concentração plasmática de corticosterona na fase de recria (Tabela 2) mostraram que a inclusão de camomila não foi capaz de exercer efeito significativo sobre esses parâmetros $(\mathrm{P}>0,05)$. SILVA et al. (2006) também não observaram efeito significativo na relação de heterófilo:linfócito quando foram utilizadas diferentes concentrações de passiflora na dieta de codornas, na fase de recria. Da mesma forma, para os resultados de concentração de corticosterona plasmática, GRAVENA et al. (2007), suplementando a dieta de codornas com valeriana, não verificaram efeitos significativos durante a fase de recria.

Os resultados da frequência dos ferimentos corporais das codornas que receberam os diferentes níveis de camomila na dieta não apresentaram diferenças significativas (dados não apresentados), levando a concluir que o uso isolado desse fitoterápico não apresentou os efeitos esperado com relação a esse parâmetro.

Para a expressão do comportamento de montas, no qual uma codorna sobe no dorso de outra, notou-se que as codornas que receberam ração contendo maior dosagem de camomila foram as que menos manifestaram esse comportamento, principalmente quando comparadas às aves submetidas ao tratamento controle (Tabela 3). Em relação ao comportamento de bicadas, no qual uma ave bica a outra, não houve esse mesmo comportamento. No entanto, as aves alimentadas com rações contendo $750 \mathrm{mg}$ de camomila $\mathrm{kg}^{-1}$ de ração permaneceram maior tempo em ócio em relação às aves submetidas aos demais tratamentos, sugerindo que as aves se tornaram menos agressivas.

Não se observam diferenças significativas para agressividade referente a bicadas agressivas (SILVA, 2006). Porém, em relação à agressividade das montas entre as aves, esse mesmo autor verificou efeito significativo, e o tratamento com $375 \mathrm{mg}$ de passiflora $\mathrm{kg}^{-1}$ de ração apresentou efeito positivo, uma vez que as aves manifestaram com menor frequência o comportamento agressivo.

Tabela 2 - Consumo diário de ração (CDR), ganho diário de peso (GDP) e conversão alimentar (CA - consumo de ração/ganho de peso), tempo em imobilidade tônica (TIT), relação H:L e concentração de corticosterona plasmática (CC) de codornas submetidas a diferentes níveis de camomila na dieta durante a fase de recria.

\begin{tabular}{llllllc}
\hline Camomila & CDR $(\mathrm{g})$ & GDP $(\mathrm{g})$ & CA & TIT (seg) & H:L & CC $\left(\mathrm{ng} \mathrm{mL}^{-1}\right)$ \\
\hline controle & 19,15 & 3,15 & 6,09 & $11,01 \mathrm{ab}$ & 0,434 & 86,89 \\
$250 \mathrm{mg}$ & 19,42 & 3,18 & 6,13 & $9,96 \mathrm{ab}$ & 0,517 & 82,64 \\
$500 \mathrm{mg}$ & 19,11 & 3,24 & 5,92 & $19,18 \mathrm{a}$ & 0,371 & 78,44 \\
$750 \mathrm{mg}$ & 18,88 & 3,02 & 6,33 & $3,96 \mathrm{~b}$ & 0,470 & 65,89 \\
Valores de F & $0,82^{\text {NS }}$ & $0,78^{\text {NS }}$ & $0,80^{\text {NS }}$ & $3,09 *$ & $2,23^{\text {NS }}$ & $0,27^{\text {NS }}$ \\
CV $(\%)$ & 3,65 & 9,25 & 9,45 & 91,33 & 26,08 & 63,43 \\
DMS & 0,97 & 0,40 & 0,80 & 14,04 & 0,16 & 69,37 \\
\hline
\end{tabular}

* Letras diferentes na mesma coluna indicam diferenças significativas $(\mathrm{P}<0,05)$ entre os tratamentos $(\mathrm{P}<0,05)$, Ns - não significativo $(\mathrm{P}>0,05)$. 
Tabela 3 - Valores percentuais de tempo médio em que codornas submetidas a diferentes níveis de camomila na dieta, durante a fase de recria, expressaram seus comportamentos.

\begin{tabular}{|c|c|c|c|c|c|}
\hline \multicolumn{6}{|c|}{ Comportamento } \\
\hline & & 0 & 250 & 500 & 750 \\
\hline Montando & \multirow{2}{*}{ Agressivos } & 16,12 & 13,03 & 15,12 & 11,79 \\
\hline Bicando & & 23,80 & 26,92 & 28,81 & 26,87 \\
\hline Comendo & \multirow{4}{*}{ Não agressivos } & 22,92 & 22,17 & 19,95 & 20,91 \\
\hline Bebendo & & 13,22 & 14,62 & 11,21 & 11,66 \\
\hline Coçando & & 19,02 & 18,39 & 19,82 & 20,53 \\
\hline Ócio & & 4,92 & 4,87 & 5,09 & 8,24 \\
\hline \multicolumn{2}{|c|}{ Total } & 100 & 100 & 100 & 100 \\
\hline \multirow{2}{*}{\multicolumn{2}{|c|}{ Valor do Qui-quadrado }} & \multirow{2}{*}{\multicolumn{4}{|c|}{$\begin{array}{l}2,46 \\
0,99\end{array}$}} \\
\hline & & & & & \\
\hline \multicolumn{2}{|c|}{ Probabilidade } & \multicolumn{4}{|c|}{0,99} \\
\hline
\end{tabular}

\section{CONCLUSÃO}

Constatou-se que a camomila, nos níveis utilizados neste experimento, não foi capaz de atuar significativamente sobre os parâmetros de desempenho, comportamento e fisiológicos, não exercendo efeito ansiolítico durante essa fase.

\section{REFERÊNCIAS}

ALBUQUERQUE, I.L. 2004. Disponível em: <http:// www.unifor.br/servlets/newstorm.noticia>. On line. Acesso em: 27 dez. 2004.

AL-MURRANI, W.K. et al. Heterophil/lymphocyte ratio as a selection criterion for heat resistence in domestic fowls. British Poultry Science, Abingdon, v.38, p.159-163, 1997.

AVALLONE, R. et al. Pharmacological profile of apigenin, a flavonoid isolated from Matricaria chamomilla. Biochemical Pharmacology, Oxford, v.59, p.1387-1394, 2000.

CAMPO, J.L.; DÁVILA, S.G. Influence of mating ratio and group size on indicators of fearfulness and stress hens and cocks. Poultry Science, Champaign, v.81, p.1099-1103, 2002.

DUARTE, M.R.; LIMA, M.P. Análise farmacopéica de amostras de camomila - Matricaria recutita L., Asteraceae. Visão Acadêmica, Curitiba, v.4, n.2, p.89-92, 2003.

DUNCAN, I.J.H. Animal behaviour and welfare. In: CLARK, J.A (Ed). Environmental aspects of housing for animal production. London: Butterworths, 1981. p.445-470.

GOMAA, A. et al. Matricaria chamomilla extract inhibits both development of morphine dependence and abstinence syndrome in rats. Journal of Pharmacological Science, Tokyo, v.92, p.50-55, 2003

GRAVENA, R.A. et al. Efeito da valeriana na dieta de codornas nas fases de recria e postura sobre o desempenho. Revista Brasileira de Ciência Avícola, Campinas, supl.8, p.62, 2006.
GRAVENA, R.A. et al. Níveis plasmáticos de corticosterona de codornas nas fases de recria e postura alimentadas com dietas contendo valeriana. Revista Brasileira de Ciência Avícola, Campinas, supl.9, p.35, 2007.

GROSS, W.B.; SIEGEL, H.S. Evaluation of the heterophil/ lymphocyte ratio as a measure of stress in chickens. Avian Disease, Kennett Square, v.27, p.972-979, 1983.

HEIBLUM, R. et al. Tonic immobility and open field responses in domestic fowl chicks during the first week of life. Applied Animal Behaviour Science, Amsterdam, v.60, p.347-357, 1998.

INSTITUTO BRASILEIRO DE GEOGRAFIA E ESTATÍSTICA - IBGE. Sistema IBGE de recuperação automática. Disponível em: <http://www.sidra.ibge.gov.br/bda/pecua/>. On line. Acesso em 07 nov. 2007.

JONES, R.B. Fear and adaptability in poultry: insights, implications and imperatives. World's Poultry Science Journal, London, v.52, p.131-174, 1996.

JONES, R.B.; MILLS, A.D. Divergent selection for social reinstatement behavior in japanese quail: Effects on sociality and social discrimination. Poultry and Avian Biology Reviews, Nothwood, v.4, p.213-223, 1999.

MACARI, M. et al. Fisiologia aviária aplicadas a frangos de corte. Campinas: FACTA, 2002. 375p.

MALHEIROS, R.D. et al. Free diet selection by broilers as influenced by dietary macronutrients ratio and corticosterone supplementation. 1. Diet selection, organ weights, and plasma metabolites. Poultry Science, Champaign, v.82, p.123-131, 2003.

MILLS, A.D.; FAURE, J.M. Panic and hysteria in domestic fowl: a review. In: ZAYAN, R.; DANTZER, R. (Eds). Social stress in domestic animals. Dordrecht : Kluwer Academic, 1990. p.248-272.

MURAKAMI, A.E.; ARIKI, J. Produção de codornas japonesas. São Paulo, Funep, 1998. 78p. 
MURAKAMI, A.E. et al. Níveis de proteína e energia em rações para codornas japonesas (Coturnix coturnix japônica) em crescimento.. Revista Brasileira de Zootecnia, Viçosa, v.22, n.4, p.534-540, 1993.

NATIONAL RESEARCH COUNCIL - NRC. Nutrient requirements of poultry. 9.rev.ed. Washington, D.C., 1994. 176p.

ROSTAGNO, H.S. et al. Tabelas brasileiras para aves e suínos. Composição de alimentos e exigências nutricionais. 2.ed. Viçosa: UFV, 2005. 186p.

SAVORY, C.J. et al. Incidence of pecking damage in growing bantams in relation to food form, group size, stocking density, dietary tryptophan concentration and dietary protein source. British Poultry Science, Abingdon, v.40, p.579-584, 1999.

SILVA, J.D.T. Uso de Passiflora alata na alimentação de codornas nas fases de recria e postura. $2006.58 \mathrm{f}$. Dissertação (Mestrado em Zootecnia) - Faculdade de Ciências Agrárias e Veterinárias, Universidade Estadual Paulista, Jaboticabal, SP.

SILVA, J.D.T. et al. Avaliação do estresse em codornas através da adição da passiflora na dieta. In: CONGRESSO DE PRODUÇÃO, COMERCIALIZAÇÃO E CONSUMO DE OVOS,
4., 2006, Indaiatuba. Anais... Indaiatuba: APA - Associação Paulista de Avicultura, 2006. p.138-139.

SILVA, J.D.T. et al. Avaliação do estresse em codornas alimentadas com passiflora na dieta nas fases de recria e postura. In: CONGRESSO DE PRODUÇÃO, COMERCIALIZAÇÃO E CONSUMO DE OVOS, 5., 2007, Indaiatuba. Anais... Indaiatuba: APA - Associação Paulista de Avicultura, 2007. p.3839.

SILVA, N.J.R. et al. Codorna é simples de criar. Campinas, SP: Coordenadoria de Assistência Técnica Integrada, n.246, 1989. 13p.

SINGH, R.V.; NARAYAN, R. Produção de codornas nos trópicos. In: SIMPÓSIO INTERNACIONAL DE COTURNICULTURA, 2002, Lavras. Anais... Lavras: Universidade Federal de Lavras, 2002. p.27-35, 2002.

STATISTICAL ANALYSIS SYSTEMS INSTITUTE. User's guide. Version 6, 4.ed. Cary, 1995. 365p.

UNSELD, E. et al. Detection of desmethyldiazepam and diazepam in brain of different species and plants. Biochemical Pharmacology, Oxford, v.38, p.2473-2478, 1989.

WECHSLER, B.; SCHMID, I. Agressive peking by males in breeding groups of japanese quail (Coturnix japonica). British Poultry Science, Abingdon, v.39, p.333-339, 1998. 